This is the author's final, peer-reviewed manuscript as accepted for publication. The publisher-formatted version may be available through the publisher's web site or your institution's library.

\title{
The influence of ethical attitudes on the demand for environmental recreation: incorporating lexicographic preferences
}

Brett R. Gelso, Jeffrey M. Peterson

\section{How to cite this manuscript}

If you make reference to this version of the manuscript, use the following information:

Gelso, B. R., \& Peterson, J. M. (2005). The influence of ethical attitudes on the demand for environmental recreation: Incorporating lexicographic preferences. Retrieved from http://krex.ksu.edu

\section{Published Version Information}

Citation: Gelso, B. R., \& Peterson, J. M. (2005). The influence of ethical attitudes on the demand for environmental recreation: Incorporating lexicographic preferences. Ecological Economics, 53(1), 35-45.

Copyright: @ 2005 Elsevier B.V.

Digital Object Identifier (DOI): doi:10.1016/j.ecolecon.2004.01.021

Publisher's Link: http://www.sciencedirect.com/science/article/pii/S0921800904004070

This item was retrieved from the K-State Research Exchange (K-REx), the institutional repository of Kansas State University. K-REx is available at http://krex.ksu.edu 
Title: The Influence of Ethical Attitudes on the Demand for Environmental Recreation: Incorporating Lexicographic Preferences

\author{
Authors: \\ Brett R. Gelso (corresponding author) \\ Economist \\ U.S. Environmental Protection Agency \\ Office of Water, Water Policy Staff \\ 1200 Penn. Ave, NW (4101M) \\ Washington, D.C. 20460 \\ Tel: 202-564-5763 \\ Fax: 202-564-0480 \\ gelso.brett@epa.gov
}

\author{
Jeffrey M. Peterson \\ Assistant Professor \\ Kansas State University \\ Department of Agricultural Economics \\ 331B Waters Hall \\ Manhattan, KS 66502 \\ Tel: 785-532-4487 \\ Fax: 785-532-6925 \\ jpeters@ksu.edu
}

Last Revised: June 2004

\begin{abstract}
This article examines the relationships between different ethical attitudes toward environmental quality and the 'use' values obtained from the environment. In particular, we consider individuals who have duty-based ethical attitudes that lead to lexicographic preferences for environmental quality. We show that individuals with duty-based ethical attitudes have recreation demand functions that are 'kinked,' exhibiting perfectly inelastic behavior over some range of income. However, the kinks cannot be identified from typical cross-sectional data, and to the extent that observed recreation demand for these individuals differs from those with neoclassical preferences, such differences could be captured empirically through a proxy variable that measures ethical attitudes. A more fundamental issue is that changes in welfare for dutybased individuals cannot be determined from their estimated demand function: while an exogenous rise in environmental quality is likely to increase their demand for recreation by these individuals, additional recreation is not the reason for an improvement in well-being. An empirical model to identify the effect of ethical attitudes on recreation is illustrated using survey data on stated preferences for visits to urban parks.
\end{abstract}

Keywords: Environmental Ethics, Protest Bids, Use Values, Lexicographic Preferences. 


\section{Introduction}

During the past few decades, economists have developed several methods for estimating the non-market value of environmental goods, but obtaining reliable and robust estimates has proved to be a challenging task. This challenge has lead to a large literature on refinements in valuation techniques (e.g., Braden and Kolstad, 1991). At the same time, a small but growing literature has considered a more fundamental issue, centering on the following questions: "Do survey respondents consider the tradeoffs between changes in income and environmental quality or do they only consider the latter? Does the notion of indifference fit into their choices?” (Edwards, 1986, p. 149). The answers to these questions quite possibly explain many of the ‘anomalous’ results in nonmarket valuation studies, such as protest bids and the large disparity between willingness-to-pay and willingness-to-accept values (Blamey and Common, 1999).

The basic insight in this literature is that some ethical attitudes give rise to lexicographic preferences, implying no possibility of tradeoffs between income and environmental preservation (Edwards, 1986; Spash, 2000). For example, someone who regards biodiversity protection as a moral duty cannot be compensated for the extinction of a species. Because lexicographic preferences cannot be represented by a utility function (Deaton and Muelbauer, 1993), such individuals lie outside the utilitarian framework on which nonmarket valuation is based.

Economists have generally dismissed lexicographic preferences as being an unrealistic special case because of their no-tradeoff property (Spash, 2000). Yet, a growing body of survey evidence suggests they are responsible for the 'nonuse' values that many people ascribe to various aspects of the environment. Several researchers have followed the suggestion of Edwards (1992), that empirical studies of nonuse values should be expanded to determine the motives that underlie survey responses. This expanded method has been applied primarily to the nonuse 
values of biodiversity protection (Stevens et al., 1991; Spash and Hanley, 1995; Blamey and Common, 1995; Common et al., 1997; Spash, 2000). All these studies found that nonuse values of biodiversity were formed by lexicographic preferences for a significant number of individuals.

In this article, we examine the relationships between different ethical attitudes toward environmental preservation and the 'use' values obtained from the environment. While previous research has established the link between ethical views and nonuse values, such views may also impact the demand for recreation activities that generate use values. In particular, we assume that all individuals have utilitarian preferences regarding recreation and other market goods, in the sense that tradeoffs between them are continuous and demands adjust to price changes. However, some individuals have duty-based ethical attitudes toward environmental preservation, and are unwilling to trade off environmental quality for changes in income, provided that income is above some threshold level (Edwards, 1986). For these individuals, a rise in environmental quality is likely to increase the demand for recreation, but additional recreation is not the reason for an improvement in their well-being.

Individuals with duty-based ethical attitudes are shown to have a recreation demand function that is 'kinked,' exhibiting perfectly inelastic behavior over some range of income. However, the kinks cannot be identified from cross-sectional data, so that observed recreation demands have the same general properties as their utilitarian counterparts. Thus, to the extent that duty-based and utilitarian demand functions would differ empirically, they could be captured through a proxy variable that measures ethical attitudes. Such an approach extends Edward's (1992) recommendation for including ethical motives into the realm of use values.

Before introducing theoretical and empirical models with different ethical attitudes affecting use values, we review the literature on the relationship between ethical attitudes and 
individual preferences in section 2. Section 3 then presents a model of recreation demand for individuals with utilitarian and duty-based ethics toward the environment. In section 4, this model is applied to estimate demand functions for recreation at urban parks for populations with different ethical views. Section 5 concludes and summarizes our findings.

\section{Ethical Attitudes and Individual Preferences}

The starting point for microeconomic analysis is the concept of a preference ordering, or a rule that ranks any two states of the world based on their relative desirability to an individual. These individual preferences must be under-girded by a set of value judgments or ethical attitudes. Environmental philosophers have discussed various types of these attitudes and their implication for the structure of preferences (e.g., Des Jardins, 1997; Glasser, 1999).

Figure 1 simplistically categorizes ethical attitudes along two dimensions: (1) how an individual reasons, and (2) who or what is taken into account in one's reasoning. The first dimension can take one of two basic forms: consequentialism and deontology (Glasser, 1999). A consequentialist considers only the consequences of an action to be important and ignores the process of achieving the goal. In contrast, a deontologist believes that decisions must be based on moral principles and that the process of achieving some goal can be judged 'wrong' if a principle is violated. The second dimension is a continuum, ranging from attitudes that consider only the decision-maker (egoism) to those that consider the entire ecosystem (ecocentrism). The figure divides these possibilities into two categories, humanism and naturalism. Attitudes in the humanist category limit moral consideration to human beings; non-human entities are given only instrumental value in improving human welfare. Naturalist attitudes are those that give independent moral standing to all or a part of nature. 


\section{The Neoclassical Paradigm}

Neoclassical economics relies primarily on utilitarianism, an ethical attitude that is both consequentialist and humanist. An individual is seen as striving to improve well being as measured by a utility function, which depends on 'market' goods that are purchased by the individual as well as 'nonmarket' goods beyond his or her direct control (e.g., the preservation of wildlife species). Concerns about the environment are thus captured as nonmarket goods that affect individual utility. Formally, if an individual's preferences over a set of $k$ goods are complete, reflexive, transitive, continuous, and strongly monotonic, then they can be represented by an ordinal utility function $u: \mathbf{R}_{+}^{k} \rightarrow \mathbf{R}$. Suppose there are $k-1$ market goods, denoted $x_{1}, \ldots$, $x_{k-1}$ and one nonmarket good, $q$. The individual's indirect utility function is then defined as $v(p, M, q)=\max _{x}\{u(x, q): p \cdot x \leq M\}$, where $M$ is money income and $p$ is the vector of prices of the market goods. The utility-maximizing level of the $i$ th market good is the demand function for that good, denoted, $x_{i}(p, M, q)$.

From the individual's point of view, the level of the nonmarket good is exogenous. The purpose of nonmarket valuation methods is to find the implicit price or the willingness-to-pay (WTP) for such a good. In particular, suppose the individual is confronted with a proposal that would increase the level of the nonmarket good from $q$ to $q^{\prime}$. The WTP for this change is implicitly defined by the equation $v\left(p, M-\mathrm{WTP}, q^{\prime}\right)=v(p, M, q)$. In the contingent valuation method, WTP is elicited through hypothetical survey questions. The most common criticism of the contingent valuation method is that hypothetical responses may not reflect true values (e.g., Hausman, 1993), and that survey respondents will find a WTP question difficult to answer because they are not accustomed to placing monetary values on nonmarket goods (Harper, 1989; 
Opaluch and Segerson, 1989). A more fundamental problem arises if respondents' ethical attitudes differ from the framework upon which valuation methods are based (Edwards, 1986). Ethical Attitudes and Lexicographic Preferences

As mentioned above, recent survey evidence suggests that many people adhere to naturalistic and deontological ethical attitudes for environmental policy decisions, and that these attitudes drive the nonuse values for biodiversity. In the context of the model above, such individuals have lexicographic preferences for $q$, which imply that continuous indifference curves between $M$ and $q$ do not exist. Thus, the preferences of these individuals cannot be represented by a utility function because the continuity condition is violated (Deaton and Muelbauer, 1993, p. 27).

Lexicographic and utilitarian preferences are compared in Figure 2 based on the model in Edwards (1986). The vertical axis of each diagram measures income $(M)$, and the horizontal axis is some environmental good such as wildlife $(q)$. The left panel depicts the indifference curves for utilitarian preferences (i.e., the level sets of $v(p, M, q)$ where $p$ is fixed). Such an individual is indifferent between $Y$ and $Z$ and would prefer either of these points to $X$. The right panel shows 'bounded' lexicographic preferences, where $M^{*}$ identifies the income level above which the environmental good is of higher priority than income. ${ }^{1} M^{*}$ can be thought of as the income needed for some minimum standard of living. Above $M^{*}$, more environmental protection is always preferred to less, regardless of the consequences to money income. Since the individual always desires the environmental good, no trade-off exists between $q$ and income above $M^{*}$ in this region. Among the three points shown, $Y$ is preferred to both $X$ and $Z$ because $Y$ corresponds

\footnotetext{
${ }^{1}$ These preferences were first applied in an environmental valuation context by Edwards (1986), although they were discussed more generally by Georgescu-Roegen (1954).
} 
to a higher level of environmental quality, while the decision maker would be indifferent between $Z$ and $X$ even though $Z$ corresponds to a higher income level.

The existence of non-utilitarian preferences has both positive and normative implications for nonmarket valuation research (Blamey and Common, 1999). The positive implication is that such preferences explain many of the observed responses to contingent valuation surveys, particularly those that are viewed as 'anomalous' from the utilitarian perspective. Edwards (1986) noted that WTP is well defined in the region above $M^{*}$ but may be very large, since the individual would be willing to pay the amount $M-M^{*}$ for any improvement in $q$. On the other hand, willingness-to-accept (WTA) for a reduction in $q$ is infinite-no amount of income could compensate the individual for a loss in the environmental good. The model therefore predicts that lexicographic individuals may not be willing to place a dollar amount on an environmental good, and will give 'protest' responses to a valuation question by reporting an inordinately large amount or else refusing to answer. ${ }^{2}$

The normative implication involves the interpretation of existence values as measured by WTP. Although WTP is well defined for lexicographic preferences, it does not measure a compensating welfare change as in the utilitarian model (Edwards, 1986). In the region above $M^{*}$ in figure 2(b), $q^{\prime}>q$ is always preferred to $q$ regardless of the associated income levels. This implies that Kaldor-Hicks potential compensation is impossible for these individuals, violating the fundamental assumption of benefit-cost analysis. Thus, aggregate WTP cannot be interpreted in the usual way as the benefits of preservation.

\footnotetext{
${ }^{2}$ Spash (2000) found that many modest-sized bids for wetland restoration were motivated by lexicographic preferences, perhaps because $M^{*}$ was close to the respondent's actual income. His alternative explanation was that the respondent felt that only a modest payment was needed to protect the resource; a larger payment would be offered if the resource became highly endangered.
} 
As noted, the economics profession has generally dismissed lexicographic preferences due to their unusual no trade-off property (Spash, 2000). However, emerging research has clearly indicated that certain economic agents are unwilling to trade off income for environmental quality due to their ethical stance (Stevens et al., 1991; Spash and Hanley, 1995; Blamey and Common, 1995; Common et al., 1997; Spash, 2000). Such preferences are one explanation for the protest bids and other 'anomalous' results in nonmarket valuation studies.

\section{A Model of Recreation Demand with Bounded Lexicographic Preferences}

This section develops a model to describe the demand for recreation under both utilitarian and lexicographic preferences for environmental quality. Let $u(x, r, q ; a)$ represent the utility function of individuals with utilitarian preferences, where $x$ is a vector of market commodities, $r$ is the number of visits to some recreation site, $q$ represents environmental quality, and $a$ is a vector of personal attributes that may affect preferences (e.g., age, gender). Welfare comparisons for such an individual can be obtained from the indirect utility function $v(p, t, M, q ; a)$ $=\max _{x, r}\{u(x, r, q ; a): p \cdot x+\operatorname{tr} \leq M\}$, where $t$ is the travel cost to the recreation site. The solutions to the maximization problem are the demand functions for market commodities and recreation. Thus, the number of recreation visits by utilitarian individual is a function of the general form

$$
r_{u}(p, t, M, q, a) .
$$

Preferences are often assumed to be such that recreation demand is decreasing in travel costs, increasing in income (i.e., recreation is a 'normal' good), and increasing in environmental quality: $\partial r_{u} / \partial t<0, \partial r_{u} / \partial M \geq 0$ and $\partial r_{u} / \partial q>0$, respectively.

Now consider deontological individuals with bounded lexicographic preferences for $q$. Each deontologist has a threshold income level $M^{*}$ above which there is no tradeoff between $M$ and $q$ (figure 2). Since well-being can only be improved by increasing $q$ if income is greater than 
$M^{*}$, a deontologist will rationally devote all income beyond $M^{*}$ to improving environmental quality. Thus, a budget of at most $M^{*}$ is devoted to $x$ and $r$. Let $\tilde{M}$ represent the income allocated to market goods, defined as $\tilde{M}=\min \left[M, M^{*}\right]$. Assuming these individuals have continuous preferences for commodities and recreation, the demands for these items can be obtained as the solutions to: $\max _{x, r}\{f(x, r ; q, a): p \cdot x+\operatorname{tr} \leq \tilde{M}\}$, where $f(\cdot)$ is a continuous function that represents the tradeoffs between $x$ and $r$. Here, $q$ enters $f(\cdot)$ purely as a parameter that affects the shape of the indifference map for $x$ and $r$, since an increase in environmental quality may affect the way allocable income is budgeted.

The deontological individual's demand for recreation is $r_{d}(p, t, \tilde{M}, q, a)$. This function is kinked in income space, since

(2) $\frac{d r_{d}}{d M}=\left\{\begin{array}{cl}\frac{\partial r_{d}(\cdot)}{\partial \widetilde{M}} & \text { if } M \leq M^{*} \\ 0 & \text { if } M>M^{*}\end{array}\right.$

Figure 3 depicts the kinked Engel curves (i.e., the demand functions in $r$ - $M$ space) for two deontological individuals with income thresholds of $M_{1}^{*}$ and $M_{2}^{*}$, respectively. As implied by equation (2), both demands are perfectly inelastic with respect income to above the thresholds. Therefore, a testable hypothesis derived from this model is that individual demand functions for deontologists have a zero income elasticity above some income level.

However, this hypothesis cannot be tested directly with typical cross-sectional data. Since the threshold values are unobservable, the kinks cannot be identified from a dataset with one observation for each individual. Points $z_{1}$ and $z_{2}$ in figure 3 represent the observations in this type of dataset. The dashed line represents the observed demand relationship for deontologists, which is a smooth function of $M$ that can be written in the general form 


$$
r_{d}(p, t, M, q, a) .
$$

Although this function is made up of points on individual demand functions that have incomeinelastic regions, $r_{d}(\cdot)$ itself may be more or less income elastic than its utilitarian counterpart $r_{u}(\cdot)$ in equation (1). For pure cross-sectional datasets, the theory predicts that the recreation demand relationship will differ across groups of individuals with distinct ethical attitudes, but the quantitative nature of the differences is an empirical issue.

\section{An Empirical Illustration: The Demand for Recreation at Urban Parks}

To illustrate the link between ethical attitudes and recreation, we empirically apply the model from section 3 to the demand for urban parks. Like many other urban areas, the city of Topeka, Kansas has recently experimented with the use of "green technologies" to manage storm-water runoff, which typically take the form of higher tree densities or constructed wetlands in public spaces. Aside from their use in water management, green technologies may also provide public benefits in the form of improved natural amenities for park visitors. To gather initial estimates of these amenity values, the Topeka Public Works Department conducted a survey that elicited likely visitation rates to parks enhanced by green technologies, ethical and environmental attitudes, and other demographic data. These data thus provide an ideal testing ground to illustrate our model.

The Data

Data were gathered from the survey mailed to municipal water patrons in Topeka. Summary statistics of the survey responses used here are in table 1; the complete survey instrument can be found in Gelso (2002). The survey elicited three groups of variables. First, households were asked about their attitudes toward water quality in Topeka and environmental policy in general. In this section of the survey, respondents were asked whether they participate 
in various local recreation activities. The responses to this question are represented by the variable REC, the ratio of the number activities indicated to the number of possibilities listed (nine). Respondents were next asked to rate the importance of various environmental issues on a Likert scale (where 1 is "not important" and 5 is "very important"); these responses were averaged to create the index variable ENVIR. The respondent's ethical attitude was then elicited by asking the following question:

How should we think about environmental policy? Check one box only.

- Decisions about the environment should be based on moral duty ("right versus wrong"). 口 Only the consequences of environmental policy are important ("benefits versus costs”).

The response to this question is the indicator variable DEON, which equals 1 if the first response was chosen (deontology) and zero for the second response (consequentialism).

The second section of the survey elicited the visitation to hypothetical parks with a high tree density and a constructed wetland. Visitation rates at different 'prices' were elicited via an indirect hypothetical method, whereby survey respondents indicate their desired number of visits to hypothetical parks at different distances from their home. The primary benefit of the method is that it aligns with households' pricing experience for the good in question; respondents are accustomed to making travel decisions for public parks but are not accustomed to paying explicit entrance fees. The survey displayed photographs of each type of park, and asked the likely number of visits to each if it were a given distance from the respondent's home and the only park in their area. The variables TREEPARK and WETPARK are the number of visits to each type of park and PRICE is the imputed travel cost based on distance. The third and final section of the survey elicited demographic attributes, which are reported in the lower portion of table 1.

The survey instrument was mailed with the August 2001 water bill to 50,000 households in Topeka and 2,551 usable surveys were returned. This implies a disappointingly low response 
rate, which probably resulted from distributing the survey with the water bill. The likely presence of non-response bias limits our ability to generalize the results to the general population of Topeka.

As Dalecki et al. (1993) noted, sample non-response bias is likely to occur very frequently with mail surveys. Unfortunately, it is difficult to test or correct for because by definition the data on the non-respondents are unavailable. Perhaps the most common feasible approach is to compare early and late survey responses, based on the assumption that the time of response is a proxy for the likelihood of responding at all. Another approach is to weight the observations in the observed sample by the ratio of over- or under-sampling of the overall population based on one or more characteristics (Dalecki et al. 1993). Because our data did not include the date at which surveys were returned and we do not have population data on the characteristics collected in the survey (such as environmental attitudes), we were not able to test or correct for the non-response bias with these methods. Nevertheless, the sample is quite large with considerable variation in most characteristics, allowing us to explore the impact of ethical attitudes for the individuals in the sample, even though the population they represent may not correspond to the general population of Topeka.

\section{Estimation}

In order to test whether ethical attitudes affect the demand for park visitation, a pooled Ordinary Least Squares (OLS) regression model was used to estimate demand coefficients for two groups of respondents. We used the Box-Cox method to evaluate alternative functional forms for the demand functions. This method transforms the dependent variable, independent variables, or both, to identify the appropriate nonlinear transformation. Pindyck and Rubinfeld (1991, pp. 240-243) define the Box-Cox model as: 
(4) $\frac{y^{\lambda_{1}}-1}{\lambda_{1}}=\beta_{0}+\sum_{i} \beta_{i}\left(\frac{x_{i}^{\lambda_{2}}-1}{\lambda_{2}}\right)+\varepsilon$

where $y$ is the dependent variable, $x_{i}$ is the ith independent variable, the $\beta$ 's are regression parameters, $\varepsilon$ is a stochastic error term, and the $\lambda$ 's are Box-Cox parameters. If $\lambda_{1}=\lambda_{2}=1$, equation (4) is equivalent to the linear form $y-1=\beta_{0}+\sum_{i} \beta_{i}\left(x_{i}-1\right)+\varepsilon$. If $\lambda_{1}=\lambda_{2}=0$, then (in the limit) equation (4) becomes the double $\log$ form $\ln y=\beta_{0}+\sum_{i} \beta_{i} \ln x_{i}+\varepsilon$. A third possibility is $\lambda_{1}=0$ and $\lambda_{2}=1$, where (4) is equivalent to the semi-exponential form $\ln y=\beta_{0}+\sum_{i} \beta_{i} x_{i}+\varepsilon$. Various models were fit with alternative values of $\lambda_{1}$ and $\lambda_{2}$, and the results were compared based on overall goodness-of-fit. These comparisons suggested the most appropriate of the three models for our demand equations was the semi-exponential form.

The estimated equations were:

$$
\begin{aligned}
\ln (\text { TREEPARK })= & \beta_{0}+\beta_{1} D E O N+\beta_{2} S E X+\beta_{3} A G E+\beta_{4} U R B A N+\beta_{5} C H I L D+\beta_{6} E D U+\beta_{7} I N C \\
& +\beta_{8} R E C+\beta_{9} E N V I R+\beta_{10} P R I C E+\beta_{11} D S E X+\beta_{12} D A G E+\beta_{13} D U R B A N \\
& +\beta_{14} D C H I L D+\beta_{15} D E D U+\beta_{16} D I N C+\beta_{17} D R E C+\beta_{18} D E N V I R+\beta_{19} D P R I C E+\varepsilon_{1} \\
\ln (\text { WETPARK })= & \beta_{20}+\beta_{21} D E O N+\beta_{22} S E X+\beta_{23} A G E+\beta_{24} U R B A N+\beta_{25} C H I L D+\beta_{26} E D U+\beta_{27} I N C \\
& +\beta_{23} R E C+\beta_{29} E N V I R+\beta_{30} P R I C E+\beta_{31} D S E X+\beta_{32} D A G E+\beta_{33} D U R B A N \\
& +\beta_{34} D C H I L D+\beta_{35} D E D U+\beta_{36} D I N C+\beta_{37} D R E C+\beta_{33} D E N V I R+\beta_{39} D P R I C E+\varepsilon_{2}
\end{aligned}
$$

where $\varepsilon_{1}$ and $\varepsilon_{2}$ are mean-zero error terms, and the variables DSEX, DAGE, DURBAN, DCHILD, DEDU, DREC, and DENVIR are slope dummy terms that represent interactions between each variable and DEON (e.g., DSEX $=\mathrm{SEX} \times \mathrm{DEON}$ ). All other variables are defined in table 1 . The slope dummy terms allow the shapes of the demand functions to differ between consequentialist and deontological survey respondents. 
PRICE and ENVIR are expected to have negative and positive effects on park visitation, respectively, but the directions of impact for other variables are unknown a priori. The impact of REC, for instance, depends on whether other recreation activities are substitutes or complements for park visitation. The signs and magnitudes of DEON and the slope dummy terms are also an empirical question; they simultaneously equal zero under the null hypothesis that ethical attitudes have no effect on visitation demand.

Results

Estimation results are provided in Table 2. As may be expected from cross sectional data, the relatively low adjusted R-squares imply that park visitation depends on a number of random factors in addition to those represented as regressors. As expected, the number of visits declines as travel costs (PRICE) increase and rises with heightened sensitivity to environmental issues (ENVIR). The positive sign on REC in both equations implies that park visits and other recreation activities are complements. Female respondents visit parks more frequently than males, and park visitation decreases with age but increases with education and income.

The null hypothesis that ethical attitudes have no effect on park visitation is rejected at the 99\% level of confidence in both the TREEPARK and WETPARK equations. ${ }^{3}$ DEON and several of the slope-shift variables are statistically different from zero at the 95\% level, implying that ethical attitudes affected both the location and shape of park visitation demand. The dummy variable DEON affects demand more strongly (both in terms of magnitude and statistical significance) than the other measures of environmental attitudes REC and ENVIR. Thus, accounting for personal ethics not only improved the statistical performance of the model, but also captured 'personal motivation' factors better than general questions about environmental

\footnotetext{
${ }^{3}$ The F-statistics for TREEPARK and WETPARK were 7.29 and 6.70, respectively, while the corresponding critical value for a $99 \%$ level of confidence was 2.32 .
} 
stewardship. Another important implication is that omitting ethical characteristics would lead to biased and inconsistent estimates of other model parameters.

To further aid in interpreting the results, table 3 reports the response elasticities of all variables for the two groups of stated ethical attitudes $(\mathrm{DEON}=0$ and $\mathrm{DEON}=1)$. Among the respondents where DEON = 1 (hereafter, "deontologists"), the elasticities for SEX are nearly zero in both equations, implying that the difference in visitation patterns among males and females is less prevalent for deontologists (table 3). Park visitation by deontologists is less sensitive to age and the number of children than visitation by consequentialists, but these effects are not statistically significant in the TREEPARK equation. Deontologists' visitation is more sensitive to income and price changes, although the difference is not statistically significant in the WETPARK equation.

Although larger (absolute) elasticities for deontologists may seem a counter-intuitive result, it is important to recall that these elasticities do not reflect the shape of individual demand functions. As illustrated in figure 3, the estimated relationship is the envelope of cross-sectional observations, each of which represents a point on a deontological individual's demand surface. Even if all observations are located on perfectly inelastic regions of individual demand curves, the estimated relationship in general will have a positive elasticity, and based on our sample, the elasticities for deontologists were generally larger than those for consequentialists.

In general, deontologists and consequentialists have aggregate demand functions with the same qualitative properties. With the exception of SEX in the WETPARK equation, all statistically significant variables affect demand in the same direction for both types of respondents (table 3). However, the significant quantitative differences in the demand functions 
are important. A model that combines the data from all households will generate misleading predictions of park visitation and welfare effects from amenity improvements.

\section{Discussion and Conclusions}

This paper has investigated the impact of ethical dichotomies on the demand for public environmental services. Stated ethical views were found to be an empirically significant determinant of the visitation demand to urban parks for a sample of Topeka survey respondents. While the consequentialist follows the traditional benefit-versus cost framework, the deontologist is concerned with a sequential ordering of goals according to right-versus-wrong. Our findings are consistent with recent literature that has also found evidence of lexicographic orderings for the nonuse aspect of environmental goods.

Interesting implications can be seen from a model that accounts for ethical attitudes that lead to lexicographic preferences. Aside from explaining the anomalous responses in applications of contingent valuation, previous literature has established that lexicographic preferences for nonuse values invalidate the method of benefit-cost analysis. The results here suggest that diversity in ethical motivations lead to a similar set of problems when estimating environmental use values. People with different ethical views have distinct use values for urban parks, and accurate depictions of the use value relationships cannot be found unless ethical motivations are explicitly captured in the empirical model. For certain groups of individuals, the recreation demand curve cannot be used to infer the welfare effects from changes in environmental quality. Further research is needed to determine the significance of environmental attitudes on other types of use values.

Individuals with duty-based ethical attitudes were also shown in this research to have a recreation demand function that is 'kinked,' exhibiting perfectly inelastic behavior over some 
range of income. However, the kinks cannot be identified from cross-sectional data with one observation per household. Developing data collection procedures and empirical methods to estimate household-level demands in this situation is an issue that warrants further research.

\section{Acknowledgements}

The views expressed in this paper are those of the authors and do not necessarily represent those of the U.S. Environmental Protection Agency. The authors wish to thank the staff of the Public Works Department in the City of Topeka for their assistance in distributing the mail survey. Helpful comments by an anonymous Ecological Economcis reviewer are also gratefully acknowledged. This research was supported in part by funds provided by the USDA National

Agroforestry Center, part of the Rocky Mountain Research Station, Forest Service, U.S. Department of Agriculture.

\section{References}

Blamey, R., Common, M., 1995. Respondents to contingent valuation surveys: Citizens or consumers?” Australian J. of Agric. Econ., 39: 263-88.

Blamey, R.K., Common, M.S., 1999. Valuation and ethics in environmental economics. In J. van den Bergh, (Editors), Handbook of Ethics and Environmental Policy, Northampton, MA, Edward Elgar, pp. 809-823.

Braden, J.B., Kolstad, C.D. (Editors), 1991. Measuring the Demand for Environmental Quality. Elsevier Science, New York.

Common, M., Reid, I., Blamey, R., 1997. Do existence values for cost benefit analysis exist? Envir. Res. Econ. 9: 225-38. 
Dalecki, M., Whitehead, J. C., Blomquist, G. C., 1993. Sample non-response bias and aggregate benefits in contingent valuation: An examination of early, late, and non-respondents. J. Envir. Manag., 38: 133-43.

Deaton, A., Muellbauer, J., 1993. Economics of consumer behavior. New York, Cambridge University Press, p. 27.

Des Jardins, J., 1997. Environmental ethics: An introduction to environmental philosophy. Wadsworth, Belmont, CA.

Edwards, S.F., 1986. Ethical perspectives and the assessment of existence values: Does the neoclassical model fit? Northeast. J. of Agric. Res. Econ., 15: 145-59.

Edwards, S.F., 1992. Rethinking existence values. Land Econ. 68: 120-22.

Fugitt, D., Wilcox, S., 1999. Cost-benefit analysis for public sector decision makers. Quorium Books, London.

Gelso, B.R., 2002. Combining revealed and stated preference data to estimate the non-market value of green technologies. Unpublished Ph.D. Thesis. Kansas State University, Department of Agricultural Economics, Manhattan, KS.

Georgescu-Roegen, N., 1954. Choice expectations and measurability. Q. J. of Econ. 68: 503534.

Glasser, H., 1999. Ethical perspectives and environmental policy analysis. In van den Bergh, J. (Editor), Handbook of Ethics and Environmental Policy, Edward Elgar, Northampton, MA, pp. 981-1000.

Harper, C.R., 1989. Rational roots of irrational behavior: Discussion. Northeast. J. of Agric. Res. Econ. 18: 96-97 
Hausman, J.A., (Editor), 1993. Contingent Valuation: A Critical Assessment. Elsevier Science, New York, NY.

Opaluch, J.J., Segerson, K., 1989. Rational roots of irrational behavior: New theories of economic decision-making. Northeast. J. of Agric. Res. Econ. 18: 81-95.

Pindyck, R., Rubinfeld, D., 1991. Econometric Models and Dconomic Forecasts. McGraw-Hill, New York, NY.

Spash, C.L., Hanley, N.D., 1995. Preference information and biodiversity preservation. Ecol. Econ. 12: 191-208.

Spash, C.L., 2000. Ecosystems, contingent valuation and ethics: The case of wetland recreation, Ecol. Econ. 24:195-215.

Stevens, T.H., Echeverria, J., Glass, R.J., Hager, T., More, T.A., 1991. Measuring the existence value of wildlife: What do CVM estimates really show?” Land Econ. 67: 390-400. 
Table 1. Variable Definitions and Descriptive Statistics

\begin{tabular}{|c|c|c|c|c|}
\hline Variable & Definition & Mean $^{\mathrm{a}}$ & $\min$ & $\max$ \\
\hline \multicolumn{5}{|c|}{ Environmental Attitudes: } \\
\hline REC & level of participation in local recreation activities (proportion) & $\begin{array}{l}0.28 \\
(0.22)\end{array}$ & 0 & 1 \\
\hline ENVIR & importance of environmental issues (Likert scale) & $\begin{array}{l}4.39 \\
(16.8)\end{array}$ & 1 & 5 \\
\hline DEON & indicator for ethical attitude ( $1=$ deontology, $0=$ consequentialism $)$ & $\begin{array}{l}0.77 \\
(0.42)\end{array}$ & 0 & 1 \\
\hline \multicolumn{5}{|c|}{ Park Visitation: } \\
\hline TREEPARK & number of visits (per year) to park with high tree density & $\begin{array}{l}14.9 \\
(21.6)\end{array}$ & 0 & 100 \\
\hline WETPARK & number of visits (per year) to park with wetland & $\begin{array}{l}8.76 \\
(16.8)\end{array}$ & 0 & 100 \\
\hline PRICE & cost of travel plus opportunity cost of time (\$/visit) ${ }^{b}$ & $\begin{array}{l}10.96 \\
5.71)\end{array}$ & 0 & 29.87 \\
\hline \multicolumn{5}{|c|}{ Exogenous Variables: } \\
\hline EDU & years of education & $\begin{array}{l}15.6 \\
(2.85)\end{array}$ & 10 & 20 \\
\hline INC & income (\$/year) & $\begin{array}{l}53339 \\
(33279)\end{array}$ & 15000 & 150000 \\
\hline SEX & gender (1=male) & $\begin{array}{l}0.45 \\
(0.49)\end{array}$ & 0 & 1 \\
\hline AGE & respondent's age in years & $\begin{array}{l}53.25 \\
(16.7)\end{array}$ & 18 & 98 \\
\hline URBAN & type of neighborhood ( $1=$ urban, $0=$ rural) & $\begin{array}{l}0.90 \\
(0.29)\end{array}$ & 0 & 1 \\
\hline CHILD & number of children in household & $\begin{array}{l}0.55 \\
(1.00)\end{array}$ & 0 & 9 \\
\hline
\end{tabular}

\footnotetext{
a Number in parentheses are standard deviations.

b Opportunity cost of leisure time was calculated 1/3 of the individual's wage rate (Fugitt and Wilcox, 1999).
} 
Table 2. Estimated Park Visitation Demand Equations

\begin{tabular}{|c|c|c|c|c|}
\hline \multirow[b]{2}{*}{ Variable } & \multicolumn{2}{|c|}{ TREEPARK Equation } & \multicolumn{2}{|l|}{ WETPARK Equation } \\
\hline & Parameter Estimate & Standard Error & Parameter Estimate & Standard Error \\
\hline INTERCEPT & $-0.2572 * * *$ & 0.1180 & $-0.2572^{* *}$ & 0.1399 \\
\hline DEON & $0.3256^{* * *}$ & 0.1368 & $0.2635^{*}$ & 0.1617 \\
\hline SEX & $-0.1288 * * *$ & 0.0256 & $-0.1176^{* * *}$ & 0.0301 \\
\hline AGE & $-0.0024 * * *$ & 0.0008 & $-0.0027 * * *$ & 0.0042 \\
\hline URBAN & 0.0623 & 0.0414 & 0.000994 & 0.0492 \\
\hline CHILD & 0.0137 & 0.0130 & -0.0212 & 0.0153 \\
\hline EDU & 0.00248 & 0.00429 & 0.00114 & 0.00513 \\
\hline INC & $0.0000039 * * *$ & 0.00000137 & 0.00000165 & 0.00000165 \\
\hline REC & $0.4443^{* * *}$ & 0.06032 & $0.6099 * * *$ & 0.0720 \\
\hline ENVIR & $0.1482^{* * *}$ & 0.0169 & $0.2297^{* * *}$ & 0.0203 \\
\hline PRICE & $-0.0256^{* * *}$ & 0.0081 & 0.0090 & 0.0098 \\
\hline DSEX & $0.1218^{* * *}$ & 0.0288 & $0.1439 * * *$ & 0.0343 \\
\hline DAGE & -0.000923 & 0.00095 & -0.0005493 & 0.00112 \\
\hline DURBAN & $-0.0855^{* *}$ & 0.0462 & -0.0074 & 0.05473 \\
\hline DCHILD & -0.0104 & 0.0049 & 0.0242 & 0.01733 \\
\hline DEDU & $0.0093^{* *}$ & 0.0049 & $0.01108^{* *}$ & 0.0059 \\
\hline DINC & $0.00000539^{* * *}$ & 0.00000155 & $0.00000451^{* * *}$ & 0.00000186 \\
\hline DREC & $-0.1425^{* *}$ & 0.0673 & $-0.2405^{* * *}$ & 0.08006 \\
\hline DENVIR & $-0.0711^{* * *}$ & 0.0202 & $-0.0754^{* * *}$ & 0.02401 \\
\hline DPRICE & $-0.0303^{* * *}$ & 0.0091 & $-0.02834 * * *$ & 0.01094 \\
\hline Adjusted $\mathrm{R}^{2}$ & 0.1798 & & 0.1830 & \\
\hline Observations & 4116 & & 3958 & \\
\hline
\end{tabular}

$\left({ }^{*}\right)$ Statistically different from zero at the $90 \%$ level of confidence.

(**) Statistically different from zero at the $95 \%$ level of confidence.

$(* * *)$ Statistically different from zero at the $99 \%$ level of confidence. 
Table 3. Elasticities at the Data Means

\begin{tabular}{|c|c|c|c|c|}
\hline \multirow[b]{2}{*}{ Variable } & \multicolumn{2}{|c|}{ TREEPARK Equation } & \multicolumn{2}{|c|}{ WETPARK Equation } \\
\hline & $\mathrm{DEON}=0$ & $\mathrm{DEON}=1$ & $\mathrm{DEON}=0$ & $\mathrm{DEON}=1$ \\
\hline SEX & $-0.58^{* *}$ & $-0.003^{\dagger+}$ & $-0.05^{* *}$ & $0.01^{\dagger+}$ \\
\hline AGE & $-0.12^{* *}$ & -0.18 & $-0.14 * *$ & -0.18 \\
\hline URBAN & 0.056 & -0.02 & 0.017 & 0.010 \\
\hline CHILD & 0.008 & 0.001 & -0.011 & 0.002 \\
\hline EDU & 0.039 & 0.18 & 0.02 & 0.19 \\
\hline INC & $0.21 * *$ & $0.50^{\dagger+}$ & -0.09 & $0.15^{\dagger}$ \\
\hline REC & $0.12^{* *}$ & $0.08^{\dagger}$ & $0.17^{* *}$ & $0.10^{\dagger+}$ \\
\hline ENVIR & $0.65^{* *}$ & $0.34^{\dagger+}$ & $1.01^{* *}$ & $0.68^{\dagger+}$ \\
\hline PRICE & $-0.28 * *$ & $-0.61^{\dagger+}$ & 0.10 & $-0.21^{\dagger+}$ \\
\hline
\end{tabular}

$*^{*}(* *)$ Statistically different from zero at the $95 \%(99 \%)$ level of confidence.

${ }^{\dagger}\left({ }^{\dagger+}\right)$ Statistically different from the DEON = 0 coefficient at the 95\% (99\%) level of confidence. 
Figure 1: Categories of Ethical Attitudes. A simplistic categorization of ethical attitudes based on two dimensions. The vertical axis represents the first dimension, based on the question "How do we reason?” While consequentialists believe that only the consequences of an action matter, deonotologists feel moral principles must be taken into account. The horizontal axis represents the second dimension that identifies, “Who or what has moral standing?” Humanists desire actions to be based solely on their beneficial results to humans, whereas naturalists feel the well being of nonhumans should be taken into account. In contrast to humanists, naturalists feel that parts of the natural world have intrinsic value independent of their benefits to human beings.

\section{Figure 2: Utilitarian and Bounded Lexicographic Preferences for Environmental Quality.}

The left panel depicts the preferences of a utilitarian individual, who considers trade-offs between income and environmental quality. An increase in income allows this individual to consume at a higher level of utility. Such an individual would be indifferent between points $Z$ and $Y$, and both these points are always preferred to point $X$. This panel illustrates the typical set of preferences traditional microeconomics analysis would assume-individuals are willing to make trade-offs among market and nonmarket goods. The right panel depicts bounded lexicographic preferences. An individual with these preferences will trade off all income above $M^{*}$ for more environmental quality. Such an individual would be indifferent between $X$ and $Z$ but would prefer $Y$ to either of these points. Above $M^{*}$, individuals obtain infinite disutility if they do not achieve their environmental quality goal; trade-offs between $M$ and $q$ are not considered. The literature has shown that this behavior may occur when individuals have a "deontological' ethical approach to consumption decisions, where an individual is solely concerned with his or her perception of right versus wrong (Glasser, 1999). 
Figure 3: Engel Curves for Recreation under Bounded Lexicographic Preferences. The Engel curves for two individuals with bounded lexicographic preferences are labeled $r_{d 1}(\cdot)$ and $r_{d 2}(\cdot)$, respectively. For income levels above the threshold $M_{i}^{*}$, person $i$ 's demand for recreation is perfectly inelastic with respect to income; the Engel curves are kinked at the threshold levels of income. Given the cross-sectional observations $z_{1}$ and $z_{2}$, the observed demand curve is represented by the dashed line, which not exhibit kinks and in general has a positive income elasticity. 


\begin{tabular}{|c|c|c|}
\hline Consequentialist & $\begin{array}{l}\text { Only consequences to } \\
\text { humans matter }\end{array}$ & $\begin{array}{l}\text { Consequences to hum ans and } \\
\text { nonhumans matter }\end{array}$ \\
\hline & $\begin{array}{l}\text { Use moral principles that take } \\
\text { only humans into account }\end{array}$ & $\begin{array}{l}\text { Use moral principles that take } \\
\text { humans and nonhumans into } \\
\text { account }\end{array}$ \\
\hline & $\mathrm{Hum}$ an ist & $\mathrm{N}$ aturalist \\
\hline
\end{tabular}

Who or what has moral standing?

Figure 1 


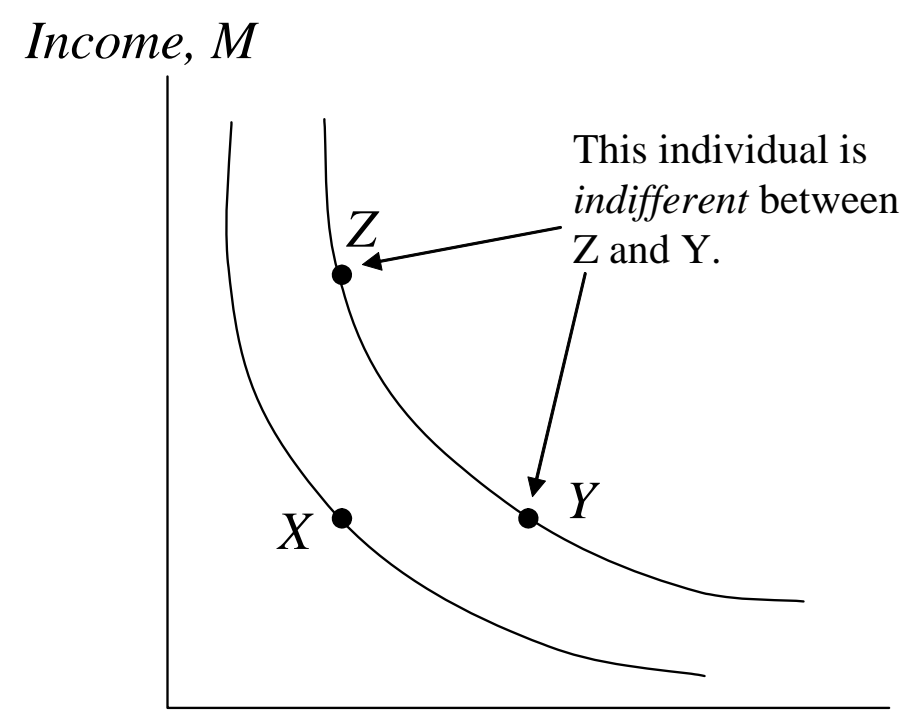

Income, $M$

Environmental Quality, q

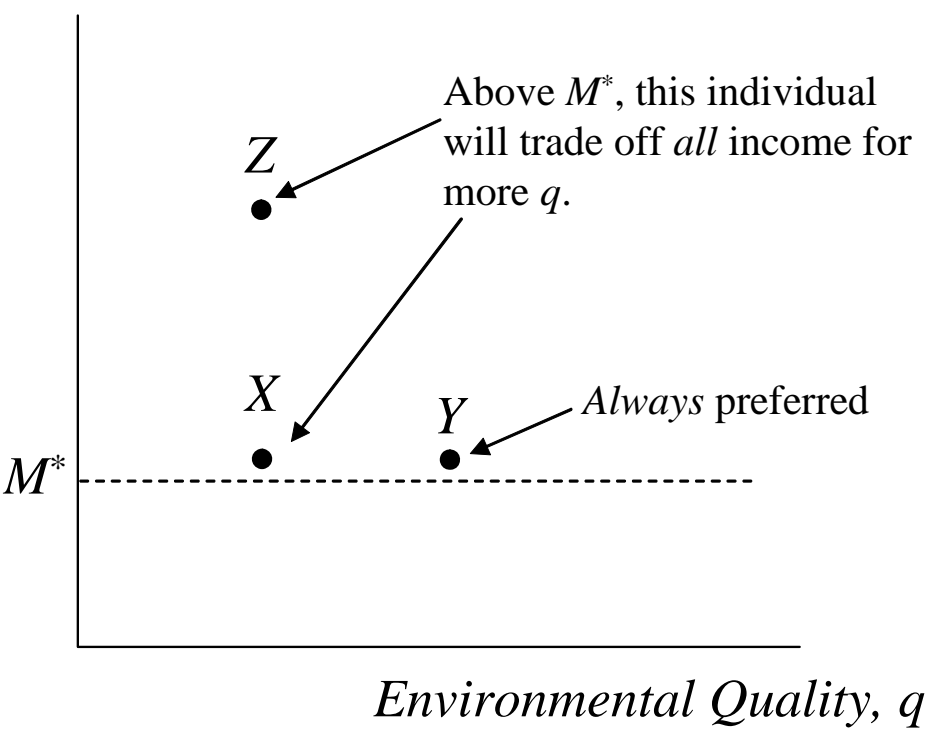

Figure 2 


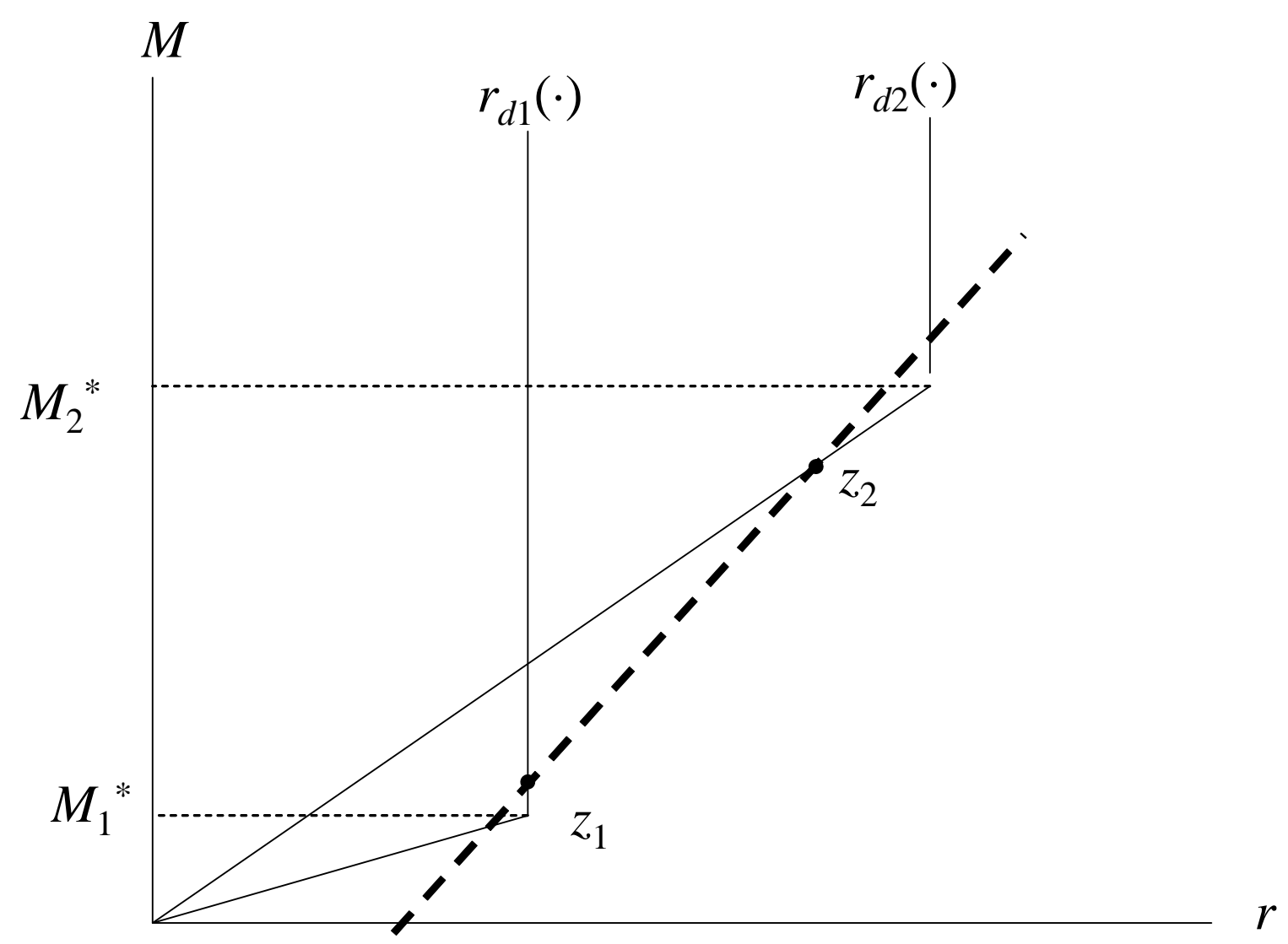

Figure 3 